\title{
The Semantics and Syntax of Prepositional Constructions with the Lexical Verb Go in Written and Spoken Discourse
}

\author{
Božana Tomić \\ PhD, Assist. Prof., Faculty of \\ Philology, Slobomir P University
}

\begin{abstract}
A prepositional construction consists of a lexical verb followed by a preposition with which it is semantically and/ or syntactically linked. The main focus of this analysis is the lexical verb go occurring within prepositional constructions. The aim of this paper is to present the frequency and distribution of prepositional verbs in written and spoken discourse. We will also determine all prepositional constructions with the lexical verb go, and present their practical use and distribution in different registers. Given that when distinguishing prepositional verbs, the semantic criteria of idiomaticity must be supplemented by syntactic criteria, we will also show all possible meanings of each prepositional construction found in the analyzed material, and determine the type of transitivity of each meaning. Furthermore, we will compare the distribution and syntactic features of each prepositional construction with the lexical verb go in different registers, and show similarities, disimilarities and all characteristics of their practical use in written and spoken discourse.
\end{abstract}

Keywords: prepositional verbs, semantics, syntax, distribution, meaning

\section{Introduction}

Prepositional verbs consist of a verb and a preposition which are closely syntactically linked with each other. As with other multi-word verbs, fronting of the prepositional complement is not normally possible (Carter, 2006, p. 434).

In using the term prepositional verb we indicate that we regard the second noun phrase in a sentence as the complement of the preposition, and not as the direct object of the lexical verb. The noun phrase following the preposition in such constructions is termed a prepositional object (Quirk, 1985, p. 1156).

Furthermore, Quirk states that in distinguishing prepositional verbs from other verb + preposition sequences, the semantic criteria of idiomaticity must be supplemented by syntactic criteria.

Đorđević divides prepositional verbs into monotransitive without the direct object and ditransitive with the direct object (Đorđević, 2007, p. 596).

Monotransitive prepositional verbs are those combinations where a preposition and the complement behave as a unit, i.e., the noun phrase that follows the preposition is not the direct 
but prepositional complement. That means that these verbs could be intransitive. Noun phrases that follow prepositions are called prepositional objects.

Unlike them, ditransitive prepositional verbs with direct objects occur with two objects - a direct and the prepositional object.

In this paper, we will analyze all possible meanings of prepositional verbs and represent their frequency and distribution in written and spoken discourse. Also, we will determine the type of transitivity of each meaning.

\section{Methodology}

The corpus used for this research consists of 300000 words and is made of three registers. The analyzed corpus is made of newspaper columns in The Guardian (politics, economy, culture, technology, and sports) analyzed during the period 2017-2019, as well as the selections of texts from American and British novels and finally, the transcriptions of various celebrities from the film industry, political scene and sports (2015-2019) which are taken from the official BBC website. The list of all materials used can be found in the Reference section. During the analysis, we combined qualitative, quantitative, and comparative methods. Qualitative and quantitative methods provide results regarding the frequency while the qualitative method enables us to see differences and similarities between analyzed register, and their syntactic features.

\section{Results and Discussion}

In analyzed registers, there are 138 examples of prepositional constructions with the lexical verb go found. They are frequently used in speech (57), and less frequently in novels (35), and The Guardian (33). Table 1 represents the list and frequency of all prepositional verbs found.

25

22

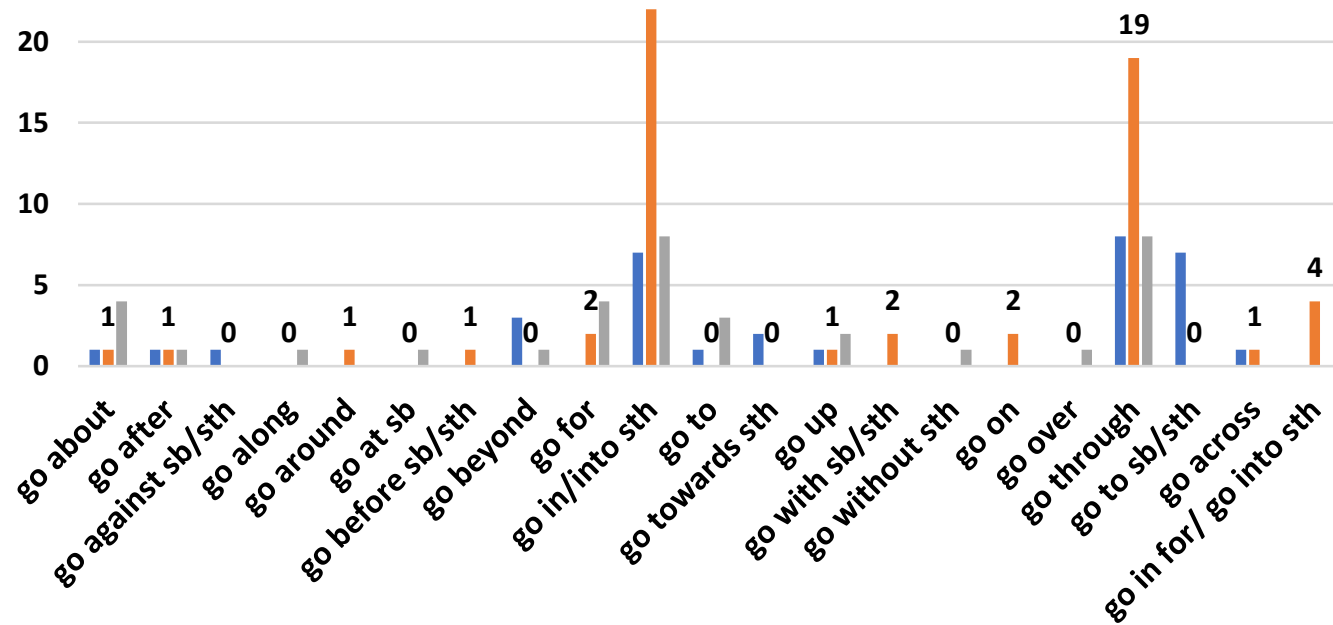

The Guardian $\quad$ Speech $\quad$ Novels

Table 1: Frequency of prepositional constructions with the lexical verb go 
As it can be seen from Table 1, the most dominant prepositional verbs are the verbs go through (48 examples found), and go in/into sth (37). Less frequent are prepositional verbs go to sb/sth (7), go about (6), and go for (6), while we registered only 4 examples of the following verbs respectively: go beyond, go to, go up, and go in for/go into sth. The combination go after occurs with 3 examples, while we registered 2 examples of the following verbs: go up. The following prepositional verbs occur with only one example in the corpus: go against sb/sth, go along, go around, go at sb, go before sb/sth, go without sth, and go over.

When talking about polysemy of prepositional combinations with the lexical verb go, they also vary. Table 2 shows all varieties in the number of meanings all found prepositional verbs show across the analyzed corpus.

\begin{tabular}{|l|l|}
\hline PREPOSITIONAL VERBS & MEANINGS \\
\hline go about & $\mathbf{3}$ \\
\hline go after & $\mathbf{1}$ \\
\hline go against sb/sth & $\mathbf{1}$ \\
\hline go along & $\mathbf{1}$ \\
\hline go around & $\mathbf{1}$ \\
\hline go at sb & $\mathbf{1}$ \\
\hline go before sb/sth & $\mathbf{1}$ \\
\hline go beyond & $\mathbf{1}$ \\
\hline go for & $\mathbf{3}$ \\
\hline go in/into sth & $\mathbf{1}$ \\
\hline go into & $\mathbf{5}$ \\
\hline go to & $\mathbf{2}$ \\
\hline go towards sth & $\mathbf{1}$ \\
\hline go up & $\mathbf{1}$ \\
\hline go with sb/sth & $\mathbf{1}$ \\
\hline go without sth & $\mathbf{1}$ \\
\hline go on & $\mathbf{1}$ \\
\hline go over & $\mathbf{1}$ \\
\hline go through & $\mathbf{7}$ \\
\hline go to sb/sth & $\mathbf{1}$ \\
\hline go across & $\mathbf{1}$ \\
\hline go in for/ go into sth & $\mathbf{1}$ \\
\hline
\end{tabular}

Table 2: Meanings of prepositional constructions with lexical verb go

\subsection{The Semantics of Prepositional constructions with the lexical verb go}

Prepositional verbs can be monotransitive without the direct object and ditransitive with the direct object. In the analyzed corpus, monotransitive prepositional verbs are more frequent, although, we found that the verbs with the same meaning behave mono- and ditranistively depending on the complementation in the clause. 


\subsection{Monotransitive prepositional constructions with the lexical verb go without the direct object}

Monotransitive prepositional verbs are those combinations where a preposition and the complement behave as a single unit, i.e., the noun phrase that follows the preposition is not the direct but prepositional complement. That means that these verbs could be intransitive. Noun phrases that follow prepositions are called prepositional objects (Đorđević, 2007, p. 596).

\subsubsection{Go through}

This prepositional verb expresses the greatest number of meanings (7), and the most frequent one is to experience or suffer sth, which is found in speech (5), The Guardian (3), and only one example in novels. Interestingly, this prepositional verb usually has compound noun phrases with another preposition as a modifier in the function of the prepositional object (a), and somewhat less frequent is universal pronoun functions as a head of the noun phrase (b):

When they are going through something important in the life of this nation, a general election, show their support for each other.

Yes, but if we end up going through each of the reliefs.

Apart from that, in speech, this verb also occurs within the wh-relative clause that functions as a subject in the simple sentence of SVC type:

No, because obviously what the UK is going through is a big constitutional change.

The meaning to look at, check or examine something closely and carefully, especially in order to find something is found in speech (5), The Guardian (2), and novels (1):

They said they had "concerns about Mr Assange's fitness" to go through the full extradition hearing, which is set for February.

In speech, the function of the prepositional complement has interrogative $w h$-clause combined with the let's imperative:

Well, let's just go through what the process is.

The meaning to perform a series of actions; to follow a method occurs in speech (4), and novels (1):

Now, having gone through that sifting process, the next stage will be even more scrutiny er, when we get to the next short list which I'll be announcing soon, but finally, the final ten will have to be subject to planning permission at the local level and all the rules that apply to any development will apply at that stage.

The next meaning if a law, a contract, bill, etc. goes through, it is officially approved, accepted or completed is less frequent, and it is registered in speech (2), and The Guardian (1).

And on Monday, the Welfare Reform Bill goes through its final stages and I think I'm right in saying something like the 16th piece of legislation since Labour came in to power in 1997, dealing with some aspects of welfare reform. 
The following meanings occur only with one example, i.e., the meaning if you go an event, a period of time, etc., you pass through it from the beginning to the end in The Guardian (a), and the meaning to pass through sth from one end to the other (figurative) in speech (b):

I know for a fact we're going through a golden age right now," he says.

I mean I've gone through this in my mind so many times.

\subsubsection{Go into sth}

This verb occurs with 5 meanings, the most dominant of which is to begin to be in a particular state or situation, which is almost equally used in speech (4), and novels (3). Unlike the previous prepositional verb, this one almost always occurs with the simple noun phrase in the function of the prepositional object:

Let's support that, let's suppose that you lose this election, that there is a referendum, you may say it is a rigged question, let's say we go into the euro, you could find yourself leading a party which would support leadership of the euro, you can imagine that can you?

In the Guardian, this verb is combined with the central modal will, while the lexical verb go is premodified by focusing subjunct largely, which has the function of particularizer:

Johnson set aside an extra $£ 2.9 \mathrm{bn}$ a year by the end of the parliament that will largely go into more nurses, GP appointments and free childcare, while Jeremy Corbyn set out an extra £83bn a year for a programme of free broadband, scrapping university fees, reversing benefit cuts and extra funding for the NHS and social care.

Equally used meaning to begin to act or behave in a particular way is registered in speech (3), and The Guardian (2):

They would have to go into that, they would have to obey that law and it hasn't happened.

The meaning to examine or discuss sth carefully is found only in speech (3), and novels (1). Interestingly, all examples in speech are within negative sentences (a), while the only example in novels is in the interrogative form (b):

a) I have met them twice, they have asked me not to go into details, but everybody knows I have met with them, so that is not a secret.

b) Does he go into detail about that?

The meaning to start taking part in an exam, competition, election, etc. occurs only in speech (2), and in both examples, this prepositional verb is combined with the semi-auxiliary be going to:

Any politician in my position, going into an election campaign, is out and hungry for every piece of support.

\subsubsection{Go about}

This verb has three meanings, and the most frequent one is to approach or deal with sth, which occurs three times in speech, and only once in The Guardian and novels respectively. In speech, this prepositional verb is used with the central modal verbs (a), and semi-auxiliaries equally (b), while in The Guardian, it is combined with the central modal verb would within the modal perfective phrase (c): 
a) If you look at the work done by Iain Duncan-Smith for us, his policy group, this summer, he produced the most comprehensive set of recommendations, far more detailed than anything that I think any major party has brought forward in recent years, has given us a real blue-print as to how we could go about doing this.

b) Prime Minister: Well, I think that it's going about as well as could be, especially, if not slightly better.

c) I never reported any of these because I had no idea how I would have gone about it, and even if I did would have had no faith in the university to take my experiences seriously.

The meaning to continue to do something is only found in novels (2), and it is used within adverbial clauses of time:

I was obliged, as I was saying, to spend some uncomfortable minutes standing in the drawing room yesterday afternoon while Mr Farraday went about his bantering.

We registered only one example of the meaning to begin to do something (to continue to do sth in your usual way especially after sth unusual has happened) in novels that occurs within the adverbial clause of time introduced with the subordinator as:

He wakes, or he thinks he does, to the sound of her hairdryer and a murmuring voice repeating a phrase, and later, after he's sunk again, he hears the solid clunk of her wardrobe door opening, the vast built-in wardrobe, one of a pair, with automatic lights and intricate interior of lacquered veneer and deep, scented recesses; later still, as she crosses and re-crosses the bedroom in her bare feet, the silky whisper of her petticoat, surely the black one with the raised tulip pattern he bought in Milan; then the business-like tap of her boot heels on the bathroom's marble floor as she goes about her final preparations in front of the mirror, applying perfume, brushing out her hair; and all the while, the plastic radio in the form of a leaping blue dolphin, attached by suckers to the mosaic wall in the shower, plays that same phrase, until he begins to sense a religious content as its significance swells - there is grandeur in this view of life, it says, over and again.

\subsubsection{Go for}

This verb occurs with three meanings in the analyzed corpus, and the most dominant one is to like or prefer sb/sth represented only in novels (3):

In a really good mood he'll go for the looser interpretations of Glenn Gould.

The meaning to apply to sb/st is found only in novels (1), and speech (1), while this meaning is not registered in The Guardian:

Would you like to go for the Scottish example where MSPs, more or less have to declare everything.

Only one example of the meaning to go to get sth is found in speech, while it is not used in the other two registers. Multi-word verb go for with this meaning occurs in the negative form within the open conditional clause:

If she doesn't go for MMR, the individual injections are better than nothing. 


\subsubsection{Go to}

The prepositional verb go to occurs with two meanings, which are almost equally represented. The meaning to start doing a particular activity or being in a particular state is found in The Guardian (1), and novels (1). Interestingly, in both examples, the head of the noun phrase in the function of a prepositional object is the noun sleep:

As a girl, Glenconner spent years away from her mother and father, having been evacuated during the war; they left her with a nanny who tied her by the wrists to her bed every night before she went to sleep.

The meaning to approach to sb/sth for help or information is found only in speech (2), while it doesn't occur in the other two registers:

So if he still had allergic rhinitis, I went to an expert and he said: 'Yep, he's on maximal treatment - antihistamines, nasal steroids, eye drops, his asthma is on the normal asthma medication but he's still got significant allergic rhinitis.'

\subsubsection{Go after}

The only meaning of this prepositional verb is to try to get or obtain sb/sth, and it occurs only once in each register respectively. In the Guardian, this verb occurs within headlines (a), while in speech it has the form of the gerund with the compound noun phrase in the function of the prepositional object (b):

a) War of words breaks out after YA novelist's fans go after critical reader

b) If you end up going after those people who are the most wealthy in society, what you actually end up doing is in fact not even helping those at the bottom end.

\subsubsection{Go against $\mathrm{sb} / \mathrm{sth}$}

The prepositional verb go against sb/sth has only the meaning to resist or opposes/sth, and it occurs in The Guardian and novels with one example respectively:

However, much of what is proposed goes against the evidence of what works when attempting to reduce crime and reoffending.

In novels, this verb occurs in the form of a gerund:

And Omar Khayyam, who had picked Rodrigues for a father, never once considered going against his tutor's wishes.

\subsubsection{Go along}

This prepositional verb occurs with the meaning to move forward of from one end of sth towards the other and is found only in novels (1):

Let the defectors go along the corridor or across town.

\subsubsection{Go around}

This verb is found only in speech with the meaning to travel in a country or a place and visit lots of different things:

As I go around the country, I find people utterly fed up by the Labour Party. 


\subsubsection{Go at sb}

The prepositional verb go at $s b$ expresses the meaning to attack somebody, and it is found only in novels (1), while in other corpora this meaning doesn't occur at all:

Through inefficient chick-blinds he spied on the couplings of the postman Ibadalla with the widow Balloch, and also, in another place, with her best friend Zeenat Kabuli, so that the notorious occasion on which the postman, the leather-goods merchant and the loud-mouthed Bilal went at one another with knives in a gully and ended up stone dead, all three of them, was no mystery to him; but he was too young to understand why Zeenat and Farida, who should by rights have hated each other like poison once it all came out, shacked up together instead and lived, after that triple killing, in unbreakable friendship and celibacy for the rest of their days.

\subsubsection{Go before sb/sth}

This verb occurs with the meaning to be presented to somebody/something for discussion, decision or judgement, and is found only in speech combined with the central modal could:

He could go before the Treasury Select Committee for example, which I know is investigating these issues.

\subsubsection{Go beyond}

This verb expresses the meaning to be greater, better, etc. than sth, and occurs in The Guardian (3), and novels (2). In the Guardian, this verb occurs within headlines (a), while in novels, it is used within nominal relative that-clause in the function of a postmodifier in a noun phrase (b):

a) Can art advance science? Researchers on the hunt for extraterrestrial intelligence are using videos, music and more to go beyond the final frontier

b) More than $90 \mathrm{bn}$ audio streams were listened to by British music fans last year but Furniss's three-year-old consultancy, which focuses on closer collaboration between the music and tourism sectors, is one of a number of new businesses tapping into a growing generation of people who seek a musical experience that goes beyond a playlist.

\subsubsection{Go in/into sth}

The prepositional verb go in/into sth expresses the meaning to join an organization, especially in order to have a career in it, and it occurs in speech (5), The Guardian (4), and novels (4). Interestingly, in speech, this verb occurs within open conditional sentences (a), and in The Guardian within nominal relative clauses in the function of the direct object (b):

a) If you go into a job centre today in this country, once you're back in work, once you've paid one month's national insurance contribution, that's a tick in the box, that's a job created.

b) There is Team Sky and BC claiming to be standing up for clean cycling and they can't even prove what was going in and out of the medical storeroom. 


\subsubsection{Go towards sth}

This verb has the meaning to be used as part of the payment for something, and it is registered only in The Guardian. In both examples, this verb occurs within the nominal thatclause in the function of the postmodifier in a noun phrase:

Under a package of policies for victims of crime, the party said it would increase by $25 \%$ the victims surcharge - a fine on offenders that goes towards refuges and community support for victims of domestic and sexual abuse.

\subsubsection{Go up}

The prepositional verb go up expresses the meaning to move from a lower position to a higher one or upstairs in a building, that is found in novels (2), and only one example in The Guardian and speech respectively:

You got to have a good pair of legs and a good pair of lungs to go up there.

In novels and The Guardian, this verb occurs within adverbial clauses of time with subordinator as, but while in Guardian, this clause is in the initial position (a), in novels is parenthetically embedded in the medial position (b):

a) As the umpire's finger went up, England could start reflecting on an innings defeat to rank alongside similar such reversals in Barbados, Auckland, Perth, Sydney, Mumbai and Chennai during recent times.

b) He feels feeble in his knees, in the quadriceps, as he goes up the stairs, making use of the handrail.

\subsubsection{Go with sb/sth}

This verb has the meaning to support a plan, an idea, etc. or the person suggesting it, and it is found only in speech (1):

Well I think we should go with the proposals that are on the table.

\subsubsection{Go without sth}

The prepositional verb go without sth occurs with the meaning to manage without something that you usually have or need, and it is registered only in novels (1):

It was too wide a tract of land to rope; he had to go without moorings.

\subsubsection{Go on}

This verb occurs with the meaning to begin doing, following, enjoying or using sth in speech only:

If we let people come out of work, go on to the dole, on to incapacity benefit, as the Tories used to, that would be disastrous.

\subsubsection{Go over}

The prepositional verb go over expresses the meaning to study something carefully, especially by repeating it, and we found only one example in novels: 
Now, in these quiet moments as I wait for the world about to awake, I find myself going over in my mind again passages from Miss Kenton's letter.

\subsubsection{Go to $\mathrm{sb} / \mathrm{sth}$}

This verb occurs with the meaning to be given to sb/sth in The Guardian (7). Interestingly, all examples found combine with the central modal verb will:

The book will go to the Brontë Parsonage Museum, the former family home in Haworth, Yorkshire, which already holds the other four surviving miniature books entitled "The Young Men's Magazines".

\subsection{Monotransitive and ditransitive prepositional combinations with the lexical verb go}

As we already stated, prepositional verbs without the direct object are structures where prepositional particles and the complement behaves as a single unit, that is, the noun is the prepositional complement, not the direct, but the prepositional object. Unlike them, ditransitive prepositional verbs with direct objects occur with two objects- a direct and the prepositional object. In our corpus, we didn't find not even one ditransitive verb exclusively, but two verbs can fall into both categories.

\subsubsection{Go across}

This verb occurs with the meaning to cross a room, a road, a river, etc. in order to get to the other side. In The Guardian, this verb occurs with the monotransitive complement (a), but in speech, it occurs with ditransitive complement with the direct object (b):

a) Some of the churches are so remote that they involve hours of hiking after hours of driving, said Rickerby: Typically, roads are washed out, you get diverted, you're going across country, there are no signposts.

b) Half the sub prime mortgages went across to Britain from America and landed people with worthless assets that they didn't wholly understand.

\subsubsection{Go in for/go into sth}

This verb has the meaning to join an organization, especially in order to have a career in it, and occurs only in speech (4), where it is equally represented as monotransitive (a), and ditransitive with the direct object (b):

a) He worked for Team Sky... then he went into BC management, which in my opinion and others he perhaps wasn't best skilled at.

b) But you know, you don't go into politics for an easy ride.

\section{Discussion}

Based on the frequency of prepositional constructions with the lexical verb go, it is obvious that they are not very frequent and are mostly used in colloquial language. Interestingly, there is a big difference in the number of examples found between the two most frequently used prepositional verbs and the rest of these constructions in the analyzed material. Also, it has to be emphasized that all highly polysemic prepositional verbs are not the most frequent ones. 
Except for the prepositional verbs go throug and go into, prepositional constructions with the lexical verb go are not polysemic, which means that their use is limited only to certain meanings.

Based on the results, prepositional constructions with the lexical verb go are almost always followed by monotransitive complementation, and expect for two verbs that are used with mono- and ditransitive complementation, there is not even one prepositional verb that is followed by ditransitive complementation pattern exclusively.

Prepositional verbs are very complex subject in the English language and they have to be analysed including both the semantic and syntactic perspective in further research.

\section{Conclusion}

A prepositional verb consists of a lexical verb followed by a preposition with which it is semantically and/or syntactically associated. Fronting of the prepositional complement is not normally possible.

The second noun phrase in a sentence is considered the complement of preposition, not the direct object of the lexical verb. Prepositional verbs can be monotransitive without the direct object and ditransitive with the direct object.

In our material, prepositional constructions with the lexical verb go are frequently used, and it is registered 138 examples of such constructions. They are dominant in speech (57), and less used in novels (35), and The Guardian (33).

The most frequent prepositional verbs are go through (48 examples found), and go in/into sth (37). Less frequent are prepositional verbs go to sb/sth (7), go about (6), and go for (6), while we registered only 4 examples of the following verbs respectively: go beyond, go to, go up, and go in for/go into sth. The combination go after occurs with 3 examples, while we registered 2 example of the following verbs: go up. The following prepositional verbs occur with only one example in the corpus: go against sb/sth, go along, go around, go at sb, go before sb/sth, go without sth, and go over.

The number of meanings of prepositional verbs also vary. The prepositional verb go through express 7 meanings, while the verb go into occurs with 5 meanings. Verbs go about and go for have 3 meanings, and the prepositional verb go to occurs with 2 meanings. The following verbs express only one meaning in analyzed registers: go after, go against sb/sth, go along, go around, go at sb, go before sb/sth, go beyond, go in/into sth, go towards sth, go up, go with sb/sth, go without sth, go on, go over, go to sb/sth, go across, go in for/go into sth.

As for transitivity, monotransitive prepositional verbs without the direct object are more dominant, although we registered that the verbs with the same meaning behave mono- and ditranistively depending on the complementation in the clause (go across \& go in for/go into sth).

The list of all prepositional verbs found along with their meanings and frequency is listed in the paper.

\section{References}

[1] Biber, D., Johansson, S., Leech G., Conrad S., Finegan E. (1999), Longman Grammar of Spoken and Written English, London: Longman. 
[2] Biber, D. (1988), Variation Across Speech and Writing, Cambridge: Cambridge University Press.

[3] Carter, R., and McCarthy, M. (2006), Cambridge Grammar of English: A Comprehensive Guide to Spoken and Written Grammar and Usage, Cambridge: Cambridge University Press.

[4] Cruse, D. A. (2000), Meaning in Language: An Introduction to Semantics and Pragmatics, Oxford: Oxford University Press.

[5] Den Dikken, M. (1995), Particles: On the Syntax of Verb-Particle, Triadic and Causative Constructions (Oxford Studies in Comparative Syntax), Oxford: Oxford University Press.

[6] Dixon, R. M. W. (2005), A Semantic Approach to English Grammar, Oxford: Oxford University Press.

[7] Đorđević, R. (2007), Gramatika engleskog jezika, Beograd: Čigoja štampa.

[8] Greenbaum, S., Quirk, R. (1990), A Student's Grammar of the English Language, Harlow: Longman.

[9] Lewis, M., (1986), The English Verb: An Exploration of Structure and Meaning, Heinle ELT.

[10] Michael, G. (2017), Syntax and Semantics of the English Verb Phrase, De Gruyter Mouton

[11] Parkinson, D., (2001), Oxford Phrasal Verbs Dictionary for learners of English, Oxford: Oxford University Press.

[12] Quirk, R., Greenbaum, S., Leech, G.,Svartvik J. [Quirk et al.], (1985), A comprehensive grammar of the English language, Harlow, Essex: Longman.

[13] Robbeets, M. (2015), Diachrony of Verb Morphology, De Gruyter Mouton.

[14] Robering, K. (2014), Events, Arguments, and Aspects: Topics in the Semantics of Verbs, John Benjamins Publishing Company.

\section{Corpus resources}

[1] Barnes, J., (1984), The Flaubert's Parrot, New York: Knopf Doubleday Publishing Group.

[2] Ishiguro K., (1989), The Remains of the Day, New York: Knopf Doubleday Publishing Group.

[3] McEwan, I., (2006), Saturday, New York: Knopf Doubleday Publishing Group.

[4] Rushdie, S., (1983), Shame, London: Picador 2000.

[5] https://www.newstatesman.com/culture/2013/12/then-later-his-ghost

[6] https://www.bbc.com/

[7] https://www.theguardian.com/international 